\title{
Apropiadoras y Poder Judicial: revisitando los discursos de la maternidad con perspectiva de género
}

\section{Female appropriators and the judiciary: revisiting the discourses of motherhood from a gender perspective}

Ana Laura Sucari anasucari@hotmail.com

Universidad Nacional de Buenos Aires, Argentina

Recepción: 19 Agosto 2020

Aprobación: 25 Febrero 2021

Publicación: 01 Junio 2021

Cita sugerida: Sucari, A. L. (2021). Apropiadoras y

Poder Judicial: revisitando los discursos de la maternidad con perspectiva de género. Aletheia, 11(22), e092. https://doi.org/10.24215/18533701e092
Resumen: Desde el retorno a la democracia, la apropiación de niños y niñas ha sido uno de los pocos delitos juzgados de forma ininterrumpida por el Poder Judicial. Sin embargo, en estas causas, las apropiadoras han recibido sistemáticamente condenas menores que los apropiadores. Partiendo del interrogante acerca de por qué varones y mujeres obtuvieron distintas condenas frente a los mismos crímenes, el artículo analiza los modos en que los discursos maternalistas y los roles de género fueron esgrimidos por las apropiadoras en sus declaraciones públicas. De este modo, se estudia con perspectiva de género los discursos de estas mujeres con el fin de examinar qué imagen buscaron construir ante el Poder Judicial, así como las intervenciones de los/las jueces/juezas en relación a la palabra de las apropiadoras y la cuestión de género.

Palabras clave: Apropiadoras, Poder Judicial, Declaraciones Públicas, Género.

\begin{abstract}
Since the return to democracy, the appropriation of children has been one of the few crimes tried continuously by the Judiciary. However, in these court cases, female appropriators have systematically received lower sentences than male appropriators. Starting from the question of why men and women obtained different sentences for the same crimes, the article analyzes the ways in which maternalistic discourses and gender roles were used by female appropriators in their public statements. In this way, the discourses of these women are studied from a gender perspective in order to examine what image they sought to build before the judiciary, as well as the interventions of the judges in relation to the word of the female appropriators and the gender issue.
\end{abstract}

Keywords: Women appropriator, Judiciary, Public declarations, Gender.

\section{INTRODUCCIÓN}

La última dictadura cívico-militar (1976-1983) se impuso con el objetivo de instaurar el neoliberalismo y reconfigurar el lazo social alegando retornar a los valores de la moral cristiana. Para ello, el gobierno de facto empleó un discurso tradicional sobre la familia y los roles que cada integrante debía cumplir al interior de ella. 
En simultáneo, el régimen desplegó el plan sistemático de apropiación de niñas y niños. El presente artículo se centrará en los usos de los discursos maternalistas por parte de las apropiadoras y el Poder Judicial. Desde el retorno a la democracia, las mujeres sistemáticamente recibieron condenas menores que sus maridos por los delitos de sustracción, retención y ocultamiento de un menor de diez años, supresión de estado civil y falsificación ideológica de instrumento público. Por lo tanto, el presente trabajo se ocupará de analizar, desde una perspectiva de género, por qué varones y mujeres obtuvieron distintas condenas frente a los mismos crímenes. Partimos de la hipótesis de que el discurso tradicional de la familia, fuertemente ligado al orden biológico, promovido por la dictadura y perpetuado durante la democracia contribuyó a atenuar la condena jurídica y social a las apropiadoras.

Para desplegar nuestra hipótesis, comenzaremos revisando el rol que ocupaban las mujeres en el modelo de familia que la dictadura buscó imponer. Luego, analizaremos los roles que ocuparon las apropiadoras en la crianza de las niñas y los niños apropiados, así como aquellas estructuras a las que buscaron autoadscribirse cuando fueron juzgadas por sus crímenes (Segato, 2003). Para ello adoptaremos la perspectiva metodológica propuesta por Claudia Feld y Valentina Salvi (2019) que plantea indagar en las percepciones de los perpetradores a partir de sus declaraciones públicas. Según las autoras, estas intervenciones producen efectos sociales, políticos y memoriales que se generan por la forma de testimoniar de cada perpetrador, el contexto y el modo en el que lo hacen, más allá de la información contenida en la declaración. En particular, los apropiadores y las apropiadoras debieron declarar públicamente en el momento de los juicios, por lo que revisaremos críticamente las sentencias y fundamentos de los juicios a Teresa Isabel González, Beatriz Alicia Castillo, María Cristina Gómez Pinto, Haydeé Raquel Alí Ahmed, apropiadoras de María José Lavalle Lemos, Gonzalo y Matías Reggiardo Tolosa, María Eugenia Sampallo Barragán y Pablo Javier Gaona Miranda respectivamente. ${ }^{1} \mathrm{Al}$ indagar en las sentencias judiciales deberemos tener en cuenta que el mundo jurídico utiliza un lenguaje específico que debe desentramarse y comprenderse para poder analizarse. El hecho de centrarnos en las sentencias responde al carácter público de dicha documentación y a que allí se reponen los hechos y testimonios más significativos de cada causa judicial. Asimismo, cada una de las intervenciones de las apropiadoras, así como las de las querellas y los propios jueces fueron producidas en un momento histórico específico, por lo que serán analizadas en relación dinámica con la coyuntura en las que se formularon. Por otra parte, se utilizarán como fuentes entrevistas y testimonios de las personas restituidas, así como declaraciones de testigos y sobrevivientes en los juicios de lesa humanidad.

\section{Discursos FAMILIARISTAS Y MODELOS DE FAMILIAS}

La dictadura adoptó un discurso tradicional y conservador sobre la familia, que implicó una reformulación de las nociones de lo público y lo privado. Las fronteras entre ambas esferas se desdibujaron, contribuyendo a que los discursos de los diversos órganos del gobierno de facto permearan en la sociedad. La familia fue considerada la célula básica de la sociedad; cada célula constituía un pilar indispensable de la misma. Como sostiene Judith Filc (1997), "la estructura social quedaba ligada al orden biológico, otorgándole carácter natural a los roles y valores familiares. El esquema se completaba representando a la Nación como la gran familia, de la cual el Estado era el padre” (pp. 42-43).

Históricamente, los discursos capitalistas sobre la familia otorgaron el protagonismo de la esfera públicaproductiva a los varones y relegaron a las mujeres a las tareas reproductivas del espacio privado, asociadas a las labores del hogar y, fundamentalmente, la maternidad. Isabella Cosse advierte que este modelo fue instituyendo un ideal de la domesticidad que:

demarcaba el 'deber ser' para varones y mujeres, pautaba la vida cotidiana, dibujaba los contornos del proyecto vital y las conductas apropiadas para las relaciones de pareja y entre padres e hijos, conectando el orden familiar con el social.(...) La domesticidad establecía, también, una clara diferenciación de roles al interior de la familia: la mujer era la 'reina del hogar', 
dedicada a las tareas de la casa y el cuidado de los niños, lo que demostraba la capacidad del jefe de la familia, cuya autoridad debía ser indiscutida, de mantenerla por sí solo (Cosse, 2006: 31).

La última dictadura se valió de estas líneas argumentativas para disciplinar a la sociedad, imponiendo una restauración conservadora que buscaba revertir los avances de la libertad de los cuerpos, la revolución sexual de los '60, los movimientos contraculturales y las relaciones sociales que desafiaban los límites impuestos por las clases dominantes. En este sentido, María Florencia Osuna señala que al interior de las familias:

el hombre-padre debía ocupar el lugar de la autoridad y la dirección, mientras que la mujer-madre debía amar a su familia, asegurando el resguardo y transmisión de la tradición. Para conservar la integridad de esta unidad moral indisoluble, era necesario evitar el ingreso de las ideas 'disolventes' controlando, particularmente, a las 'secciones débiles' de la pared de la 'célula': los niños y jóvenes de la familia. Se consideraba que por medio de ellos se propagaba el virus de la 'subversión' y los responsables de que esto no ocurriera eran el padre y la madre (Osuna, 2017: 173).

La familia se encontraba permanentemente expuesta al peligro de la cooptación de los hijos por parte de la "subversión", entendida como una enfermedad que debía ser extirpada del cuerpo social. Este argumento otorgaba a los padres -y esencialmente a las madres, quienes en este modelo eran las encargadas exclusivas de la crianza- la responsabilidad por las acciones de sus hijos. En otras palabras, si los/las jóvenes adoptaban una ideología "subversiva", era culpa de sus progenitores por la mala educación impartida; padres y madres se convertían en los garantes del comportamiento de sus hijos.

Por lo tanto, la dictadura promovió modelos parentales específicos. Sin embargo, estos patrones ideales encontraban su reverso cuando las mismas figuras aparecían ligadas a la "subversión". Tanto en las cárceles como en los centros clandestinos de detención (CCD), el régimen de facto subvirtió el orden de género y sexual actuando contra su propio discurso familiarista y restauracionista (D’Antonio y Rodríguez Agüero, 2019). De esta forma, las experiencias de embarazo y maternidad en espacios de encierro implicaron formas específicas de violencia contra las mujeres. Tal como señala Débora D’Antonio (2016), los agentes penitenciarios y/o militares llevaron adelante un proceso de desmaternalización que supuso la degradación y maltrato de las prisioneras madres y el deterioro intencional del lazo filial. En esta misma línea, Victoria Álvarez sostiene que "así como fueron víctimas de torturas particularmente dirigidas a atentar contra sus embarazos y cuestionarlas en su condición de mujeres, madres y militantes, sus cuerpos fueron instrumentalizados en función del nacimiento de los/as hijos/as que, como parte del mismo plan, serían apropiados/as" (Álvarez, 2017: 50). Así, la apropiación tuvo entre otros objetivos otorgar a los niños "familias normalmente constituidas", es decir educarlos y formarlos en el seno de familias conformadas bajo el modelo tradicional.

Como ya ha sido ampliamente probado por los organismos de derechos humanos y el Poder Judicial, este trabajo parte de la concepción de que la apropiación constituyó una práctica sistemática, específica y generalizada. ${ }^{2}$ La misma consistió en la sustracción, retención y ocultamiento de la identidad de los hijos e hijas de los militantes políticos. Parte de las niñas y los niños apropiados fueron criados por militares y civiles relacionados con el accionar dictatorial, quienes buscaban separarlos de sus familias y educarlos con una ideología distinta -opuesta- a la de sus padres.

A partir del secuestro, asesinato y desaparición de sus hijos e hijas, y la apropiación de sus nietos y nietas, un grupo de madres y abuelas se nuclearon revirtiendo los sentidos asignados a la maternidad.

En un principio, las Madres y Abuelas de Plaza de Mayo se organizaron en torno a un discurso sobre la familia opuesto a los sentidos otorgados por la dictadura. El régimen de facto agredía a las mujeres en lo más consustancial de su identidad según el lugar social asignado para ellas, por lo que en sus orígenes las Madres y las Abuelas pedían por sus hijos en tanto su rol "natural" se los requería o invocando el lazo biológico los unía; sin embargo, con el correr del tiempo las organizaciones se fueron consolidando y creando nuevos sentidos. El escenario elegido trascendió el ámbito privado de lo doméstico e irrumpió en la arena pública, específicamente en el centro del poder político: la Plaza de Mayo. Más aún, estas mujeres no se consideraban 
-únicamente- madres y abuelas de sus propios hijos y nietos, sino de Plaza de Mayo, reconociéndose en ese simple acto de nominación como Madres y Abuelas de todos los desaparecidos y todos los menores apropiados. ${ }^{3}$ Esta socialización de la maternidad (Filc, 1997) puso en cuestión uno de los puntos centrales del discurso tradicional de la familia: la maternidad ligada al ámbito privado-doméstico, e individual. Por otra parte, el reconocerse Madres y Abuelas de la plaza las situó en un espacio que socialmente no estaba asignado para ellas. Al combinar las tareas de cuidado del ámbito doméstico con las de la militancia, que en algunos casos era previa a la desaparición de sus hijos/as (D’Antonio, 2006), se produjo una nueva configuración en la cual el rol maternal y mujeril ya no se reafirmaba en los pilares tradicionales asignados a aquellas categorías, sino en unos nuevos. Así, la filiación ya no dependía del lazo sanguíneo, sino de la experiencia política compartida (Filc, 1997).

Siguiendo los modelos de familia hegemónica y en contraposición a las "malas madres subversivas" y "las locas de la plaza", las parejas apropiadoras se esforzaron por conformar familias tradicionales, dentro de las cuales cada integrante desempeñara estrictamente los roles sociales asignados para ellos. Del mismo modo, cuando los niños/jóvenes restituyeron su identidad y los apropiadores debieron enfrentar procesos judiciales, las apropiadoras buscaron presentarse como buenas mujeres y, por consiguiente, como buenas madres.

\section{Argumentos maternales en las declaraciones de las apropiadoras y SENTENCias JUDICIALES}

En el presente apartado indagaremos en las declaraciones públicas de las apropiadoras con el fin de analizar qué imagen buscaron construir en los estrados. Para ello, nos valemos del aporte de un campo de estudios más amplio destinado a la investigación del accionar de las parejas apropiadoras y los procesos judiciales por apropiación. En particular, partimos del trabajo de Sabina Regueiro (2012) en el cual a través del estudio de una restitución de la década del '80 demuestra cómo los actores intervinientes se entrelazaban con una trama social y política afín a la dictadura por lo que se opusieron a la restitución. Asimismo, incorporamos el enfoque de Laura Oren (2001) respecto al carácter "ineludiblemente político" del derecho familiar, tanto en la noción del interés superior del niño/a, como en los procesos judiciales, indefectiblemente ligados al contexto social en el que se llevan a cabo. Por otra parte, al estudiar las representaciones teatrales sobre la apropiación, María Luisa Diz señala que "a falta de declaraciones públicas de la apropiadora, su personaje se construyó a imagen y semejanza del personaje del apropiador" (Diz, 2020: 289) o bien se las ubicó directamente fuera de escena. Este artículo busca realizar un aporte específico, diferenciando la palabra pública y las autorrepresentaciones de las apropiadoras dentro del universo de los apropiadores.

Para ello, examinaremos las declaraciones de las apropiadoras y sus defensas a partir de la revisión crítica y con perspectiva de género de las sentencias en tanto fuentes históricas. ${ }^{4}$ Siguiendo a Feld y Salvi comprendemos que "cada declaración implicó despliegues performativos, actos de habla, posicionamientos axiológicos, y presentaciones de sí mismo[a] que hizo cada declarante" (Feld, Salvi, 2019: 30). Sin embargo, las autoras no incorporan una definición de la categoría de "represor/a" ni perspectiva de género, por lo que quedan por afuera del análisis un conjunto de sujetos y prácticas que complejizan el accionar represivo cívico militar del período.

Por último, indagaremos en las intervenciones de los/las jueces/juezas en relación a la actuación de las apropiadoras y la cuestión de género, a pesar de que en estas causas ésta no haya sido considerada como un prisma específico de análisis. Siguiendo a María José Sarrabayrouse (2011), consideramos que la intervención de cada Juez/a estuvo regida, a la vez, por las reglas generales del derecho y sus relaciones personales y creencias; así como también por la coyuntura histórica en la que se desarrolló. 


\section{“RECIÉN HABÍA NACIDO Y TENÍA EL OMBLIGUITO MAL ATADo"}

Mónica María Lemos, militante trotskista y Gustavo Antonio Lavalle, militante de Montoneros, fueron secuestrados en julio de 1977 junto a su hija de un año. La pareja fue llevada a la Brigada de Investigaciones de San Justo y luego al Pozo de Banfield. Mónica estaba embarazada de ocho meses: María José nació durante el cautiverio de su madre. A los pocos días, fue apropiada por Teresa Isabel González, Suboficial de la Brigada de Investigaciones de San Justo, y Nelson Rubén, quienes la inscribieron como hija propia. En 1987 María José conoció sus orígenes, gracias a los resultados arrojados por el Banco Nacional de Datos Genéticos (BNDG). En consecuencia, se inició una causa en el Juzgado Federal de Morón a cargo del Juez Federal Juan María Ramos Padilla. ${ }^{5}$ El juicio se desarrolló entre la sanción de las leyes de Punto Final y Obediencia Debida y los indultos, en un contexto de creciente impunidad; sin embargo en 1987 Ramos Padilla había declarado la inconstitucionalidad de dichas leyes, lo que suponía una novedad en relación con los magistrados heredados de la dictadura que perduraban en el Poder Judicial. Asimismo, se trató de la primera causa judicial en la cual la relación con el régimen de facto la mantenía la mujer. Finalmente, el 19 de enero de 1988 se dictó sentencia contra Teresa Isabel González y Nelson Rubén, condenando a cada uno a tres años de prisión en suspenso [ver Cuadro 1].

En su declaración, Teresa González sostuvo que "vino una persona de la Brigada de San Justo, no me pregunte quién doctor porque no me acuerdo, y me entregó a María José que recién había nacido y tenía el ombliguito mal atado. Yo antes habia hecho un comentario que me gustaria tener un hermano para mi hija $y$ pienso que por eso me trajeron a María José." Asimismo, González alegó querer colaborar para:

encontrar la verdadera familia de María José y tener una buena relación con ellos, ser familiares, para que mi hija no sufra tanto, por eso le voy a decir todo lo que sé (...). La persona que me trajo a la nena me dijo que acababa de nacer, que venía del 'Pozo de Banfield' y que era hermana de otra chiquita.

Para comenzar, podemos observar que González se refirió a su deseo de maternidad. Esta referencia la ubicó en el lugar esperado para ella: como "buena mujer" tenía latente dicho deseo. Por otro lado, reforzó el amor hacia la niña. Sin embargo, gracias a los testimonios de sobrevivientes de la Brigada de San Justo, María José supo que cuando sus padres ingresaron al CCD "González se iba a quedar con mi hermana, pero que le habían sugerido que se quedará conmigo que iba a estar recién nacida”. ${ }^{8} \mathrm{Al}$ quedarse con la niña recién nacida e inscribirla como hija propia, González buscó ocultar su inserción en el plan sistemático de apropiación. No obstante, al momento de declarar buscó construir una imagen materna/al. Más aún, en su declaración detalló las atenciones que tenía con los prisioneros dentro del CCD donde se desempeñaba:

les traía ropa de mi marido y hacía todo lo que humanamente podía. Yo les traía de la cocina todo lo mejor que podía, porque la comida que traía estaba en mal estado casi siempre, los presos me habían escrito una cartita dándome las gracias por lo que hacía por ellos y me la hicieron quemar. ${ }^{9}$

Como se puede observar, las acciones descritas corresponden a tareas de cuidado asociadas a labores femeninas, más que a su rol en la repartición de toxicomanía y a su rango de suboficial de la policía bonaerense.

Por otra parte, en el fundamento de la sentencia, el licenciado en psicología interviniente Roberto Saunier:

describió la situación y la personalidad de la apropiadora, como estructurada sobre la creencia de que sería factible tener un hijo sin la presencia de un hombre y agregó que este 'tener' no se refiere a concebir sino a poseer; dio cuenta después de las patologías que se entrecruzaban en el grupo familiar que encabezaban los procesados, destacando una figura masculina débil a la vez que paradojalmente se llamaba a la niña con su segundo nombre, quedándole así un nombre de varón. ${ }^{10}$

El fallo abordó la cuestión genérica presentando los roles de los apropiadores al interior de la estructura familiar. A fines de la década del ochenta, el licenciado en psicología describió la conformación familiar con el término "patología”; no obstante, este no se refería a la apropiación, sino a la debilidad de la figura masculina y, 
por oposición, la predominancia de la figura femenina al interior de la pareja/familia. Sin embargo, al realizar un análisis situado, sostenemos que no se trató de una patología sino más bien de una construcción genérica a partir de los roles que González y Rubén desempeñaban socialmente. Al respecto, Mariana Sirimarco señala que:

la policia es una institución que presta una desmesurada atención a la masculinidad. Referirse a un sujeto masculino no implica, sin embargo, aludir necesariamente a los hombres (...) La masculinidad bien puede ser ejercida por mujeres. Así, en el caso de la agencia policial, no resulta extraño encontrarse con anatomías femeninas que exhiben significantes propios del mundo de lo masculino (Mariana Sirimarco, 2004: 71).

En definitiva, González había adquirido significantes masculinos para desenvolverse tanto dentro de la institución policial como en el ámbito doméstico.

En este sentido, en el juicio por la Brigada de San Justo en el año 2018, se definió a la sargenta apropiadora como una persona muy violenta, que se mudaba seguido para ocultar a la niña, pero siempre alardeaba públicamente de lo que había hecho. Se sostuvo que González robaba bienes de los operativos que realizaban los represores de San Justo, práctica habitualmente asociada a los grupos de tareas compuestos por sujetos masculinos ${ }^{11}$. Sin embargo, al estar imputada por la apropiación de María José, González optó por abandonar los significantes masculinos y buscó construir su figura vinculada a los significantes de la feminidad, resaltando frente al Juez aquellos gestos asociados a una imagen femenina y maternal. Dicho de otro modo, en la instancia judicial la apropiadora buscó "feminizarse" con el fin de aprovechar el imaginario social compartido construido en torno a la mujer/madre.

Cabe señalar que Ramos Padilla no recibió acríticamente el discurso de la acusada; en la sentencia afirmó que el fundamento de la paternidad no puede ser el manifestado por Teresa Isabel González, que se origina en el deseo de apropiación y en la mentira. Esto invalida todo su sentimiento materno-filial, pues se construye esa relación en base a una mentira y a una relación enfermiza, que en definitiva es un vínculo entre sometedor y sometido. Por un lado, resulta importante destacar la relevancia teórica y social del argumento del Juez en un contexto en que, como se viene analizando, los fundamentos de maternidad no eran cuestionados; por otro, la cuestión no fue valorada como agravante, otorgándole a González la pena mínima.

Por último, tanto el Juez de primera instancia como el Tribunal de apelación, compuesto por los Drs. Hugo Rodolfo Fossati, Jorge Eduardo Barral y Marta Herrera, imputaron a ambos apropiadores por los mismos delitos y les otorgaron la misma pena, sin considerar como agravante el hecho de que González hubiera estado directamente relacionada con el accionar dictatorial e hiciera uso de su rol como sargenta de la policía bonaerense para hacerse de una menor. ${ }^{12} \mathrm{Al}$ respecto, Alessandro Baratta sostiene que:

el hecho de que el sistema de la justicia criminal posea como destinatarios sobre todo a sujetos que desempeñan papeles masculinos (...) explica la mayor benevolencia, así como la relativa tranquilidad con la cual, en la aplicación judicial de la ley, han sido sancionadas penalmente las mujeres, si se las compara con los varones que cometieron los mismos delitos. La 'deferencia' con la cual parecen ser tratadas las mujeres en los juicios penales encuentra su explicación, sobre todo, en la 'preocupación' del sistema de la justicia criminal (de género masculino) en limitar su propia interferencia negativa sobre el cumplimiento de los roles conferidos a las mujeres en la esfera de la reproducción (Baratta, 2000: 63-64).

$\mathrm{Al}$ construir su discurso en torno a significantes femeninos, el rol de González dentro de la policía bonaerense no fue considerado como agravante al momento de mensurar la pena. Al otorgarle la misma condena que a su marido, observamos que no se ponderó el ámbito laboral/público de la apropiadora, que era donde se desplegaba su relación con el régimen represivo. Como veremos a continuación, en el caso de los varones la pertenencia a las Fuerzas Armadas o de seguridad fue calificada como agravante. 


\section{"Yo SOY LA QUE MÁS SUFRo"}

Juan Enrique Reggiardo y María Rosa Ana Tolosa, militantes Montoneros, fueron secuestrados en febrero de 1977 y llevados a "La Cacha”, CCD de la ciudad de La Plata. María Rosa estaba embarazada de seis meses y esperaba mellizos. Antes de dar a luz, fue trasladada al Penal de Olmos, donde nacieron Gonzalo Javier y Matías Ángel Reggiardo Tolosa el 27 de abril de 1977. Veinte días después, los hermanos fueron apropiados por Samuel Miara, subcomisario de la Policía Federal, y Beatriz Castillo, quienes los anotaron y criaron como hijos propios. En 1989 fueron extraditados de Paraguay, donde se encontraban prófugos, para que los jóvenes se realizaran los análisis inmunogenéticos.

Para el presente trabajo se revisó la sentencia impuesta el día 19 de diciembre de 1995 por los Jueces Martín Irurzun, Eduardo Luraschi y Horacio Cattani, la cual fue resultado de la apelación a la primera sentencia realizada en 1994, en pleno período de impunidad. El fallo de segunda instancia condenó a Samuel Miara a doce años de prisión y a Beatriz Castillo a cinco años y seis meses, elevando las penas de ambos acusados respecto a las dispuestas por la Cámara de primera instancia; a la vez que absolvió a Castillo del delito de falsificación ideológica de documento público por las actas de nacimiento, partidas de nacimiento y DNI de los mellizos [ver Cuadro 1].

En este caso, resulta indispensable hacer una breve descripción de los acontecimientos precedentes. En febrero de 1977, Castillo estaba embarazada de siete meses y, mientras se encontraba con su marido en Mar del Plata, debió ser intervenida quirúrgicamente extrayéndole un feto sin vida a causa de asfixia intrauterina. Al ser dada de alta, retornó a su departamento fingiendo que el embarazo seguía su curso. Dos meses después, el matrimonio realizó un nuevo viaje del cual volvieron con los mellizos. Miara y Castillo inscribieron a los niños como propios, simulando que eran sus hijos biológicos. Cabe destacar que esta práctica excedió ampliamente al crimen de apropiación; tal como ha demostrado Carla Villalta (2012), las extendidas formas de adopciones ilegales funcionaron como condiciones de posibilidad para las apropiaciones.

Como se planteó anteriormente, los matrimonios apropiadores buscaron conformar familias tradicionales ciñéndose al modelo hegemónico de la domesticidad. Cada lugar de la estructura familiar asignaba un poder diferencial a cada uno/a de los/as miembros/as: los hombres tenían más poder que las mujeres y, a menudo, ejercían poder sobre ellas. En el caso de Miara, al ser subcomisario de la Policía Federal y agente de la represión, consideramos que no sólo hacía sentir su autoridad al interior del circuito $\mathrm{ABO}^{13}$, sino que también ejercía su dominación al interior del hogar y sobre su esposa.

A pesar de que en los fundamentos los magistrados dejaron en claro que "como parte importante de la ocultación, simularon la continuación del embarazo perdido, apariencia que Beatriz Alicia Castillo de Miara sostuvo en connivencia con su esposo" ${ }^{14}$; reforzaron la noción naturalizada de la subordinación femenina frente a las decisiones de un sujeto masculino. En este sentido, Irurzun -quien pertenecía a la "familia judicial” (Sarrabayrouse, 2011) y en julio de 1994 había sido ascendido con acuerdo del Senado a la Cámara Federal- expresó:

Cabe remarcar en relación a Samuel Miara, que no sólo tuvo a su alcance medios institucionalizados para restituir los menores a su lugar de origen - máxime estimando que su función era representar la ley, agravándose su responsabilidad además por el grado que ostentaba en la Policía Federal y el destino que le fue asignado en aquella época-; sino que se valió de la capacidad o del resorte represivo que ellos le proporcionaban para obrar en forma disvaliosa. (...) Mientras que la acusada, si bien tuvo una activa intervención en los graves episodios descriptos, no debe olvidarse que, como se ha demostrado, se trató en todo momento de una actitud complementaria sin mayor protagonismo direccional. ${ }^{15}$

Aquí, la pertenencia a la institución policial fue considerada agravante de la responsabilidad de Miara. Por otra parte, el argumento de la "actitud complementaria" de la esposa/madre esgrimido en esta causa, no se ciñe únicamente al espectro de las apropiadoras, sino que responde a una concepción sobre el rol de la/ $s$ mujer/es. El Poder Judicial, institución históricamente patriarcal, no sólo normalizó los significantes de 
género proclamados desde otras instituciones y la sociedad civil, sino que como sostiene Tamar Pitch: "el derecho y los derechos son por tanto sexuados, y las modalidades de su sexualización, por un lado responden a los modos de organización social dominantes, y por otro no solo los legitiman y contribuyen a perpetuarlos, sino que son uno de los factores que los producen" (Pitch, 2010: 440). ${ }^{16}$

En otra sentencia por apropiación impuesta en 1993, el Juez Federal Roberto José Marquevich dictaminó que: "con respecto a [la apropiadora] valúo como atenuante su imposibilidad de ser madre, con lo que todo ello conlleva en los aspectos físicos y psicológicos de una mujer" ${ }^{17} \mathrm{El}$ hecho de que en la década del noventa un Juez Federal considerara la imposibilidad de maternar de forma biológica como atenuante ante un delito de lesa humanidad da cuenta de la fuerte impronta socialmente asignada a la maternidad: era/debía ser uno de los principios rectores de la vida de las mujeres. Estos casos dejan ver que los magistrados no cuestionaron los razonamientos maternalistas como lo hicieron con otros pasajes de las declaraciones de los/las apropiadores/ as, ya que formaban parte del sentido común.

Asimismo, estos casos ponen en evidencia la complejidad de los roles de género. Por un lado, Castillo participó direccionalmente en la apropiación de los Reggiardo Tolosa haciendo uso de su propio cuerpo para ocultar el delito, entre otras acciones. Sin embargo, eso no la substraía de la opresión genérica a la que se veía sujeta para acatar con los mandatos del ideal de la domesticidad, que incluía en sus bases la maternidad.

Si bien analizar en su totalidad los complejos caminos que se entrecruzaron en la restitución de los Reggiardo Tolosa excede los propósitos de este acotado trabajo, resulta imperativo tener presente que en los primeros meses de 1994 el caso adquirió una importante repercusión mediática. ${ }^{18}$ Desafiando las órdenes judiciales, Castillo asistió al programa de televisión conducido por Bernardo Neustadt y, frente a las cámaras, expresó:

ellos saben que yo los adoro, yo también sé que ellos me adoran. Acá hay muchos problemas en el medio para que los chicos puedan vivir con nosotros. (...) Yo soy la que más sufro. [Estuvieron conmigo] Desde los dos o tres días [de vida]" A lo que Neustadt acotó 'Usted es la madre'. ${ }^{19}$

En consonancia, en su declaración judicial Castillo "hizo mención que para dedicarse a los niños dejó todo, incluso su carrera, donde estaba cursando Ciencias Económicas, faltándole solamente seis materias, no dejando en nadie la crianza de los mismos". ${ }^{20}$ Las citas precedentes dan cuenta del modo en que la apropiadora apeló al amor y a su propia actuación como madre -relegando sus asuntos personales en pos de la maternidadpara construir su figura, tanto ante el Tribunal como ante la sociedad.

\section{"El VÍNCULO CON ESTE TIPO DE PERSONAS QUEDA DETERMINADO POR LA CRUELDAD Y LA PERVERSIÓN"}

María Eugenia Sampallo Barragán nació en 1978 durante el cautiverio de sus padres Mirta Mabel Barragán y Leonardo Rubén Sampallo, ambos militantes del PCML. Fue apropiada por Osvaldo Arturo Rivas y María Cristina Gómez Pinto, quienes la anotaron como hija propia y durante su infancia le contaron diversas historias sobre su origen. Cuando el BNDG confirmó la filiación biológica de María Eugenia en el año 2001, se inició una causa judicial contra sus apropiadores y contra Enrique José Berthier, capitán del ejército que había entregado a la niña. Este caso tuvo la particularidad de ser el primero en que la persona restituida fue querellante contra sus apropiadores. Asimismo, durante los casi siete años que duró la tramitación de la causa, hubo un gran cambio en las políticas memoriales en Argentina. A partir de 2004 se abrió un período de proliferación de políticas de Memoria, Verdad y Justicia; entre ellas, se derogaron las leyes de impunidad, lo que significó la reapertura de los juicios de lesa humanidad. En otras palabras, a la par del transcurso del juicio, las políticas públicas de derechos humanos comenzaron a formar parte de la agenda pública. En este contexto, el 4 de abril de 2008 el TOF N 5, compuesto por Guillermo 
Gordo, Daniel Horacio Obligado y Ricardo Luis Farías dictó sentencia contra los tres imputados. A Rivas se lo imputó por un delito más que a su ex esposa, por lo que se lo condenó a una pena mayor [ver Cuadro $1] .^{21}$

En la instancia judicial se hizo gran hincapié en la mala relación que María Eugenia tenía con Osvaldo Arturo Rivas y, especialmente, con María Cristina Gómez Pinto. La defensa se esforzó por justificar que esta mala relación tenía "que ver más con cuestiones subjetivas propias de una familia disfuncional, producto de un pésimo matrimonio y que ello debe haber sido consecuencia de la estructura psicológica y psiquiátrica de sus asistidos, en especial de Gómez Pinto”. ${ }^{22}$ Así, se buscó limitar el maltrato al orden doméstico/privado. Sin embargo, al erigirse ella misma como querellante, María Eugenia demostró que el maltrato era fruto del crimen de apropiación, por lo que concernía al ámbito público. Si bien, a priori, podría caracterizarse como "normal" que hijas y madres se peleen; la querella expuso un razonamiento eficaz al argumentar que la mala relación no correspondía solamente a un mal vínculo entre la adulta y la niña característico de una relación filial conflictiva, sino que se cimentaba en el crimen de la apropiación y se perpetuaba en el trato brindado por la primera hacia la segunda: "los procesados Gómez Pinto y Rivas no eran y no son familia para la Querellante. Ellos fueron y son quienes la mantuvieron oculta durante décadas y la forma en que lo hicieron no es una cuestión subjetiva de orden privado, sino que es un aspecto de un delito" ${ }^{23}$ De esta forma, la querella puso de manifiesto el modo en que las prácticas sociales genocidas (Feierstein, 2007) de la dictadura en general y de la apropiación en particular, se inmiscuyeron en las relaciones familiares, hasta entonces comprendidas únicamente como ámbito de actuación privada. Al momento de la sentencia, el Tribunal atendió la demanda de la querella, al dictaminar que "respecto de Gómez Pinto, debe considerarse también como agravante, el maltrato continuo que infligió a la víctima durante su niñez y adolescencia”. ${ }^{24}$

Por otro lado, la defensa utilizó diferentes recursos para alegar que Gómez Pinto era psíquicamente inestable: "[el] examen psicológico (...) da cuenta de su verborragia expresiva, denotando tensión, ansiedad, rigidez verbal y gestual, cierta impulsividad, configuración con egocentrismo y tendencia a la sobre elaboración. Apuntó, con relación a la ansiedad persecutoria larvada, la irritabilidad, los componentes histéricos y sicopáticos y la tendencia a la sobrevaloración fabulatoria” ${ }^{25}$ El conjunto de las características citadas por los magistrados desde el campo de la psicología buscaban resaltar rasgos negativos asociados al género femenino en el imaginario popular - por ejemplo, la histeria-. Contrariamente, en ninguna parte de esta sentencia - ni de las otras que se analizan en este artículo- la defensa apeló a las características tradicionalmente asociadas a la masculinidad; en el caso de los varones, los abogados recurrieron a otras estrategias tales como la ajenidad al régimen represivo, la falta de antecedentes penales, escasa formación y tipo de empleo, confiando en que éstas serían más efectivas para atenuar la condena de los apropiadores.

Por último, la defensa buscó instalar que el delito de apropiación cesó en 1989 cuando Gómez Pinto llevó a la niña al BNDG ante el pedido de Abuelas. Si bien el resultado no había sido concluyente respecto a las muestras disponibles en el banco, los abogados sostuvieron que a partir de aquel momento el Estado contaba con los datos de la menor. Ese hecho demostraría la predisposición de Gómez Pinto de colaborar, cuando "se podría haber negado a concurrir o se podría haber fugado llevándose a la niña consigo". ${ }^{26}$ Así, la defensa parece insinuar que habría "apropiadores verdaderos", con conocimiento de los delitos que estaban cometiendo, mientras que otros habrían actuado de buena fe. En respuesta a este tipo de sugerencias, cinco días antes de la lectura de la sentencia a sus apropiadores, María Eugenia Sampallo Barragán sostuvo que:

En cuanto al término 'padres del corazón', imagino que se hace referencia a cierta relación filiatoria a partir del afecto. Pero entonces podemos preguntarnos si una persona que robó a un recién nacido, que le ocultó que fue robado, que tal vez secuestró o torturó a sus padres, que lo separó de ellos y de su familia, que le mintió siempre respecto de sus orígenes, que lo maltrató, humilló, engañó, en forma cotidiana, que lo separó de su familia a conciencia, si una persona que hizo todo esto, o algo de todo esto, puede saber y sentir qué es el amor filial. Yo respondo que no, que el vínculo con este tipo de personas queda determinado por la crueldad y la perversión. ${ }^{27}$ 
Por su parte, el Tribunal desestimó el planteo de la defensa acerca de la prescripción del delito, juzgando que la retención y ocultamiento de un menor de diez años constituye un delito permanente, el cual cesa únicamente cuando la persona conoce su identidad biológica. ${ }^{28}$

\section{"LE HACÍA MILANESAS"}

Pablo Javier Gaona Miranda, hijo de Ricardo Gaona y María Rosa Miranda, militantes del PRT-ERP, nació el 13 de abril de 1978 en el Hospital Rivadavia. A los treinta y un días de vida fue secuestrado junto a sus padres, y entregado a Salvador Norberto Giribone y Haydée Raquel Ali Ahmed, quienes lo anotaron como hijo propio y lo llamaron Leandro. Desde pequeño le dijeron que era adoptado, haciendo coincidir su historia con la de sus hermanas de crianza: como Giribone y Ali Ahmed no podían tener hijos, habían viajado a Misiones a "buscarlos" y no contaban con datos de sus padres biológicos. En el año 2001 Pablo sintió las primeras dudas sobre su identidad, pero no fue hasta siete años después que le preguntó a su apropiadora si podía ser hijo de desaparecidos. Ella confirmó su sospecha, pero le advirtió "no digas nada porque vamos a ir presos". En 2012 Pablo se presentó en Abuelas y fue el primer nieto restituido luego del Juicio Plan Sistemático, cuya sentencia probó la sistematicidad y generalidad de la práctica de apropiación. En ese marco, Giribone y Ali Ahmed fueron condenados el 9 de septiembre de 2014 por los Drs. Oscar Hergott y Ángel Nardiello y la Dra. Adriana Palliotti [ver Cuadro 1]. ${ }^{29}$

En su declaración, Ali Ahmed manifestó que "Leandro era periodista deportivo así que iba los domingos [a la casa de los apropiadores], y ella le hacía milanesas, o comida, para la semana aunque no le faltara. Ella le dijo que no importaba si se llamaba Pablo, que lo que importaba era que fuera agradecido de la vida" ${ }^{20}$. En primer lugar, Ali Ahmed aludió a las tareas de cuidado relacionadas a la alimentación. Como se planteó anteriormente, las declaraciones no son únicamente los dichos de los/las imputados/as, sino también sus sentidos performáticos, de este modo, se considera que la referencia a "las milanesas" excede a la tarea de preparar la comida. En Argentina, las milanesas remiten a una "buena comida", a la calidez del ámbito hogareño, a las ligaduras familiares. Por lo tanto, se considera que Ali Ahmed y su defensa buscaron (re)crear esa sensación al referirse a que "le hacía milanesas": las "buenas madres" cuidan de sus hijos y les preparan milanesas porque a ellos les gustan. Luego, la apropiadora expresó que no le importaba cómo se llamara el joven, dejando entrever que lo aceptaría de manera incondicional como solamente quienes son "verdaderas madres" hacen, lo cual nos lleva a preguntarnos: ¿por qué lo llamó Leandro en la oración precedente? En una entrevista realizada por la autora, Pablo cuenta que incorporó ese nombre en el mismo momento que restituyó su identidad: "Yo cuando veo la partida de nacimiento y Claudia [Carlotto] me pregunta '¿Cómo querés que te llame?' Yo le digo, 'Bueno, si mis viejos me pusieron Pablo, llamame Pablo, quiero que me llamen Pablo' (...) Me hice cargo enseguida del nombre, no me costaba”. ${ }^{31}$ Entre el momento de su restitución y el juicio, mantuvo el contacto con sus apropiadores, por lo que no hay posibilidad de que Ali Ahmed no supiera que había decidido cambiar su nombre. Por lo tanto, es posible que el hecho de llamarlo Leandro no respondiera a una cuestión de costumbre o confusión; sino que fuera un sometimiento más al que se lo intentó reducir.

Por otra parte, el Tribunal estableció que ambos apropiadores eran responsables del delito de la apropiación:

La responsabilidad de Salvador Norberto Giribone y de Haydee Raquel Ali Ahmed, debe ser analizada bajo los parámetros de la coautoría funcional (...) 'El elemento esencial de la coautoría es el codominio del hecho. Cada uno de los coautores tiene en sus manos el dominio del hecho a través de la parte que le corresponde en la división del trabajo. El codominio del hecho requiere una decisión conjunta al hecho. Mediante esta decisión conjunta o común se vinculan funcionalmente los distintos aportes al mismo'. En este orden de ideas, advertimos que, tanto Salvador Norberto Giribone y Haydee Raque Ali Ahmed, efectuaron aportes funcionales dentro de la división de roles que les ocupó en el curso causal de estos acontecimientos. ${ }^{32}$ 
Si bien cabe destacar que a Giribone se lo condenó por el delito de falsedad ideológica de documento público, acusándolo de un delito más que a su mujer - por lo que se le imputó una pena mayor-; los Jueces entendían que la apropiación devenía de una decisión conjunta y sostenida en el tiempo de la cual ambas partes del matrimonio habían participado y actuado en connivencia. Esta caracterización difiere de la propuesta por el magistrado Irurzun en el caso de los mellizos Reggiardo Tolosa quien, como ya analizamos, sostenía que la apropiadora había tenido una "actitud complementaria sin mayor protagonismo direccional". El cambio de perspectiva se relaciona tanto con las consideraciones personales de cada Juez, como con la transformación de la coyuntura histórica de ambas sentencias. Mientras que la primera se dio en un contexto de impunidad, en el 2014 habían proliferado las políticas de Memoria, Verdad y Justicia y el juicio a múltiples actores -y en menor medida actrices- de la represión formaba parte de la agenda pública. Paralelamente, Ali Ahmed también era consciente de este proceso, por lo que frente a la interpelación de Pablo respondió "no digas nada porque vamos a ir presos".

\section{CUADRO 1}

\begin{tabular}{|c|c|c|c|c|c|c|c|c|}
\hline Nombre & $\begin{array}{l}\text { Teresa Isabel } \\
\text { González }\end{array}$ & Nelson Ruben & $\begin{array}{l}\text { Beatriz Alicia } \\
\text { Castillo }\end{array}$ & $\begin{array}{l}\text { Samuel } \\
\text { Miara }\end{array}$ & $\begin{array}{l}\text { María } \\
\text { Cristina } \\
\text { Gómez Pinto }\end{array}$ & $\begin{array}{l}\text { Osvaldo } \\
\text { Arturo Rivas }\end{array}$ & $\begin{array}{l}\text { Haydeé } \\
\text { Raquel Alí } \\
\text { Ahmed } \\
\end{array}$ & $\begin{array}{l}\text { Salvador } \\
\text { Norberto } \\
\text { Giribone } \\
\end{array}$ \\
\hline $\begin{array}{l}\text { Apropiador/a } \\
\text { de }\end{array}$ & $\begin{array}{l}\text { María José } \\
\text { Lavalle } \\
\text { Lemos }\end{array}$ & $\begin{array}{l}\text { María José } \\
\text { Lavalle } \\
\text { Lemos }\end{array}$ & $\begin{array}{l}\text { Gonzalo y } \\
\text { Matías } \\
\text { Reggiardo } \\
\text { Tolosa } \\
\end{array}$ & $\begin{array}{l}\text { Gonzalo y } \\
\text { Matías } \\
\text { Reggiardo } \\
\text { Tolosa } \\
\end{array}$ & \begin{tabular}{|l|} 
María \\
Eugenia \\
Sampallo \\
Barragan \\
\end{tabular} & \begin{tabular}{|l} 
María \\
Eugenia \\
Sampallo \\
Barragan \\
\end{tabular} & $\begin{array}{l}\text { Pablo Javier } \\
\text { Gaona } \\
\text { Miranda }\end{array}$ & $\begin{array}{l}\text { Pablo Javier } \\
\text { Gaona } \\
\text { Miranda }\end{array}$ \\
\hline Pena & $\begin{array}{l}3 \text { años en } \\
\text { suspenso }\end{array}$ & $\begin{array}{l}3 \text { años en } \\
\text { suspenso }\end{array}$ & $\begin{array}{l}5 \text { años y } \\
6 \text { meses }\end{array}$ & 12 años & 7 años & 8 años & 6 años & 8 años \\
\hline Delitos & $\begin{array}{l}\text {-Sustracción, } \\
\text { retención y } \\
\text { ocultamiento } \\
\text { de una menor } \\
\text { de diez años. } \\
\text {-Falsificación } \\
\text { ideológica de } \\
\text { instrumento } \\
\text { público } \\
\text { destinado a } \\
\text { acreditar la } \\
\text { identidad de } \\
\text { una persona } \\
\text { (partícipe } \\
\text { necesaria). }\end{array}$ & $\begin{array}{l}\text {-Sustracción, } \\
\text { retención y } \\
\text { ocultamiento } \\
\text { de una menor } \\
\text { de diez años } \\
\text { (partícipe } \\
\text { necesario) } \\
\text {-Falsificación } \\
\text { ideológica de } \\
\text { instrumento } \\
\text { público } \\
\text { destinado a } \\
\text { acreditar la } \\
\text { identidad de } \\
\text { una persona }\end{array}$ & $\begin{array}{l}\text {-Coautora de } \\
\text { los delitos de } \\
\text { retención y } \\
\text { ocultamiento } \\
\text { de menores de } \\
10 \text { años (dos } \\
\text { hechos). } \\
\text {-Falsedad } \\
\text { ideológica de } \\
\text { documento } \\
\text { público } \\
\text { cometido en } \\
\text { dos } \\
\text { oportunidades } \\
\text { en grado de } \\
\text { partícipe } \\
\text { necesaria } \\
\text { [certificados } \\
\text { médicos de } \\
\text { nacimiento]. }\end{array}$ & $\begin{array}{l}\text {-Coautor de } \\
\text { los delitos de } \\
\text { retención y } \\
\text { ocultamiento } \\
\text { de menores de } \\
10 \text { años (dos } \\
\text { hechos). } \\
\text {-Falsedad } \\
\text { ideológica, por } \\
\text { declaraciones } \\
\text { falsas en } \\
\text { instrumentos } \\
\text { públicos } \\
\text { cometida } \\
\text { también en } \\
\text { dos } \\
\text { oportunidades, } \\
\text { en grado de } \\
\text { partícipe } \\
\text { necesario } \\
\text { [certificados } \\
\text { médicos de } \\
\text { nacimiento]. } \\
\text {-Falsedad } \\
\text { ideológica de } \\
\text { documento } \\
\text { público } \\
\text { cometida en } \\
\text { dos } \\
\text { oportunidades } \\
\text { en grado de } \\
\text { autor [actas } \\
\text { Registro Civil } \\
\text { y DNI]. }\end{array}$ & $\begin{array}{l}\text {-Retención y } \\
\text { ocultamiento } \\
\text { de una menor } \\
\text { de diez años. }\end{array}$ & $\begin{array}{l}\text {-Retención y } \\
\text { ocultamiento } \\
\text { de una menor } \\
\text { de diez años. } \\
\text {-Falsedad } \\
\text { ideológica en } \\
\text { instrumento } \\
\text { público } \\
\text {-Falsedad } \\
\text { ideológica en } \\
\text { instrumento } \\
\text { público } \\
\text { destinado a } \\
\text { acreditar la } \\
\text { identidad de } \\
\text { las personas. }\end{array}$ & $\begin{array}{l}\text {-Ocultamiento } \\
\text { y retención de } \\
\text { un menor de } \\
\text { diez años. } \\
\text {-Alteración } \\
\text { del estado } \\
\text { civil de un } \\
\text { menor de diez } \\
\text { años. }\end{array}$ & $\begin{array}{l}\text {-Ocultamiento } \\
\text { y retención de } \\
\text { un menor de } \\
\text { diez años. } \\
\text {-Alteración } \\
\text { del estado } \\
\text { civil de un } \\
\text { menor de diez } \\
\text { años. } \\
\text {-Falsedad } \\
\text { ideológica de } \\
\text { documentos } \\
\text { públicos } \\
\text { destinados a } \\
\text { acreditar la } \\
\text { identidad de } \\
\text { las personas. }\end{array}$ \\
\hline
\end{tabular}

El cuadro presenta de forma sencilla y esquemática las penas impuestas a las/los apropiadoras/es, así como los delitos por los que se las/los condenó en las sentencias analizadas. El objetivo del mismo es que la información pueda ser examinada tanto de forma individual -cada persona en su singularidad-, como comparativamente, al interior de las parejas apropiadoras y/o entre varones-mujeres. 


\section{REFLEXIONES FINALES}

A lo largo del artículo examinamos los modelos hegemónicos de familia y analizamos los usos del discurso tradicional del rol de la mujer y la maternidad esgrimidos por las apropiadoras en sus declaraciones públicas. Si bien dista de nuestro propósito establecer generalidades, ya que comprendemos las diversas subjetividades y relaciones con el régimen represivo de cada persona; a partir del análisis de casos resulta posible trazar ciertas reflexiones finales.

En todos los casos desarrollados, las mujeres apelaron tanto a su condición de género, como a su rol de madres, a modo de estrategia para presentarse ante los jueces y la audiencia. Remarcamos que no sólo lo hicieron ante los magistrados, sino también ante sus pretendidos hijos/as, sus familias biológicas y la sociedad en general. Es posible proponer que los argumentos sobre el amor por los/las niños/niñas/jóvenes no estuvieran únicamente destinados al Poder Judicial o a reducir su condena jurídica; sino que a través de ellos también intentaran perpetuar el vínculo con los niños/niñas y sus familias biológicas. Al contrastar las declaraciones de los/las apropiadores/as y los testimonios de las personas restituidas surgen nuevos interrogantes acerca del vínculo que continúan -o no- teniendo luego de la restitución y los procesos judiciales. Si bien estos exceden los límites del artículo, quedan abiertos como parte de una futura agenda de investigación: ¿Qué importancia tienen las tareas de cuidado realizadas por las/os apropiadoras/es durante el tiempo de convivencia en la continuidad del vínculo que los/las jóvenes restituidos mantienen con ellos/ as al tiempo que forjan una relación con su familia biológica? ¿Cómo se transforman las funciones materna y paterna a partir de las pruebas judiciales por apropiación y las declaraciones de las/los apropiadores?

Por otra parte, en los casos en que los apropiadores tuvieron condenas más altas que las mujeres, se les imputaron más delitos que a ellas. No obstante, como se desprende de los fundamentos, la tarea de mensurar la pena no resulta únicamente de la sumatoria de delitos; por ello, a continuación se retomarán algunas consideraciones acerca de los efectos de las intervenciones de las apropiadoras.

En las fuentes analizadas se evidencia el modo en que varones y mujeres fueron tratados diferencialmente. Mientras que el rol de Teresa González dentro de la policía no fue considerado como agravante, la relación del Subcomisario Samuel Miara con el régimen militar sí lo fue.

Por otro lado, las apropiadoras apelaron a las tareas de cuidado asociadas a las labores femeninas. González manifestó su predisposición por el cuidado de los prisioneros dentro del CCD, resaltando así su vocación maternal. Ali Ahmed se refirió a las tareas de cocina construyendo su figura como buena ama de casa y buena madre al preparar la comida que le gustaba a "su hijo". Por su parte, Castillo sostuvo su rol de madre de los mellizos, autopercibiéndose la "madre del corazón”, papel que en el contexto de impunidad en el que se desarrolló la restitución de Gonzalo y Matías fue sostenido por los medios de comunicación. En el único caso que no se hizo referencia al cuidado o amor fue en el de Gómez Pinto: consideramos que se debió a que el vínculo afectivo entre la apropiadora y la niña se había quebrado mucho tiempo antes de que el BNDG arrojara los resultados de la filiación biológica de María Eugenia. De este modo, a través de sus discursos, las apropiadoras buscaron hacer uso de una "imago materna" que formaba parte del imaginario social compartido sobre el rol de las mujeres. Sus declaraciones fueron utilizadas como escenarios para reforzar sus autoadscripciones al rol femenino tradicional.

En relación a las estructuras de poder, hemos observado que estas mujeres se encontraban condicionadas por lo que sus maridos y la sociedad en general esperaban de ellas. Sin embargo, no debemos perder de vista que ellas también han sido portadoras de violencia. Así, si bien las opresiones se ejercieron de manera cruzada y fragmentada, las apropiadoras tuvieron un rol activo en la apropiación de las/los niñas/os; y al momento de ser juzgadas se valieron de los discursos tradicionales sobre la familia buscando identificarse y ser identificadas- con significantes femeninos.

Para concluir, resulta pertinente acentuar que el derecho penal es un sistema de control del orden público; "la esfera de la reproducción, del intercambio sexual de una pareja, de la procreación, de la familia y de la 
socialización primaria, en otras palabras, el orden privado, no es objeto del control ejercido por el derecho penal" (Baratta, 2000, p. 60). Como hemos analizado, en los juicios por apropiación se aplicó el sistema penal o poder punitivo público a mujeres que articularon sus defensas en torno a discursos del orden privado. Las estructuras y significantes asociados a varones y mujeres se encontraban tan arraigadas en nuestra sociedad que fueron esgrimidas por las apropiadoras a modo de defensa, y aceptadas como naturales por los distintos actores del Poder Judicial. En efecto, ellos reprodujeron el derecho sexuado, legitimando las estructuras genéricas imperantes, en lugar de cuestionarlas.

A treinta y siete años del retorno a la democracia, este trabajo permite repensar las miradas sobre los sujetos de la represión, amplificando el espectro de sus actores y actrices. Confiamos en que al complejizar y precisar los/las actores/actrices de la represión -Fuerzas Armadas y de seguridad, eclesiásticos, empresarios, médicos/as, parteras, apropiadores/apropiadoras- podremos comprender nuestra historia reciente de forma más sistémica e integral.

\section{REFERENCIAS}

Álvarez, V. (2017). ¿No te habrás caído?” La experiencia concentracionaria durante la última dictadura (1976-1983) desde una perspectiva de género. Memorias y marcos sociales de la escucha entre la dictadura y la transición a la democracia, Tesis de posgrado inédita. Universidad Nacional de La Plata, Facultad de Humanidades y Ciencias de la Educación, La Plata, Argentina.

Baratta, A. (2000). El paradigma del género. De la cuestión criminal a la cuestión humana. En H. Birgin (comp.), Las trampas del poder punitivo (pp. 39-83). Buenos Aires: Ed. Biblios.

Cosse, I. (2006). Estigmas de nacimiento. Peronismo y orden familiar 1946-1955. Buenos Aires: Fondo de Cultura Económica.

D’ Antonio, D. (2016). La prisión en los años setenta: Historia, género y política. Buenos Aires: Ed. Biblos.

D’Antonio, D. y Rogríguez Agüero, L. (2019). El carácter sexo-genérico de la represión estatal en la Argentina de la década del setenta, Sémata. Ciencias sociales y humanidades, 31, pp. 53-69.

Diz, M.L. (2020). Declaraciones públicas y artes escénicas: la construcción de personajes y narrativas de apropiadores y apropiadoras en Teatro x la identidad (2000-2001), Kamchatka. Revista de análisis cultural, 15, pp. 271-292.

Feierstein, D. (2007). El genocidio como práctica social. Entre el nazismo y la experiencia argentina. Buenos Aires: Fondo de Cultura Económica.

Feld, C. y Salvi, V. (eds.) (2019). Las voces de la represión. Declaraciones de perpetradores de la dictadura argentina. Buenos Aires: Miño y Dávila.

Filc, J. (1997). Entre el parentesco y la politica. Familia y dictadura, 1976-1983. Buenos Aires: Editorial Biblos.

Oren, L. (2001). Righting Child Custody Wrongs: The Children of the Disappeared in Argentina, Harvard Human Right Journal, 14, pp.123-195.

Osuna, M.F. (2017). La intervención social del Estado. El Ministerio de Bienestar Social entre dos dictaduras (Argentina, 1966-1983). Rosario: Prohistoria.

Pitch, T. (2010). Sexo y género de y en el derecho: el feminismo jurídico. Anales de la Cátedra Francisco Suárez, 44, pp. 435-459.

Regueiro, S. (2012). Apropiación de niños, familias y justicia. Argentina (1976-2012). Rosario: Prohistoria.

Rosenberg, M.I. (1996). Aparecer con vida. Apuntes sobre filiación, identidad y restitución de los niños secuestradosdesaparecidos, 1976-1982. En S. Tubert (comp.), Figuras de la Madre. Madrid: Ediciones Cátedra, pp. 259-282.

Sarrabayrouse Oliveira, M. J. (2011). Poder judicial y dictadura: el caso de la Morgue Judicial. Buenos Aires: CELS.

Segato, R. (2003). Las estructuras elementales de la violencia. Quilmes: Universidad Nacional de Quilmes.

Sirimarco, M. (2004). Marcas de género, cuerpos de poder. Discursos de producción de masculinidad en la conformación del sujeto policial, Cuadernos de Antropología Social, 20, pp. 61-78. 
Villalta, C. (2012). Entregas y secuestros. El rol del Estado en la apropiación de niños Buenos Aires: Editoriales del Puerto, CELS.

\section{Notas}

1 La elección de los casos estuvo determinada por las diversas coyunturas socio-históricas en los que se desarrollaron, con el fin de analizar los discursos de las apropiadoras y los magistrados en distintos momentos. Asimismo, para la selección de los casos se tuvo en cuenta su heterogeneidad, con el objeto de alumbrar diversas aristas de los procesos de restitución y de juzgamiento, así como las particularidades de cada historia.

2 El 5 de julio de 2012 el Tribunal Oral Federal Núm. 6, presidido por la Jueza María del Carmen Roqueta, dictó sentencia de la causa "Juicio Plan Sistemático por Apropiación de Niños", en la cual se juzgó 34 casos de apropiación y se probó la sistematicidad y generalidad del robo de bebés.

3 Resulta evidente que no hubo tantas Madres como desaparecidos/as. Como expresa una Madre: "hubo madres que no pudieron enfrentar las dos situaciones, (...) los dos frentes, porque después de todo era como dos dictaduras, la dictadura doméstica y la dictadura militar" (Rosenberg, 1996: 263). El testimonio demuestra que, tal como lo plantearon las feministas a principios de los años '80, el terrorismo de Estado era efectivamente un terrorismo patriarcal.

$4 \mathrm{Al}$ examinar las penas dispuestas a varones y mujeres, no se sugiere que las condenas a los apropiadores y/o entregadores debieron ser menores, sino analizar los argumentos esgrimidos por los magistrados al condenar a unos y a otras. Por otra parte, el trabajo con las declaraciones de las apropiadoras no significa en ningún caso una reproducción acrítica de sus palabras.

5 Los juicios por apropiación son tramitados en el fuero penal federal ya que juzgan delitos de lesa humanidad.

6 Juzgado Federal Sec. N 2 de Morón, s/ “Gonzalez, Teresa Isabel, Rubén, Nelson s/infracción Art. 146 del Código Penal”, Sentencia del 19/1/1988. El subrayado es propio.

7 Ibídem (19/1/1988), p. 8.

8 Brigada de San Justo: Declararon las nietas María y María José Lavalle, 29/8/2018 Abuelas de Plaza de Mayo, s/n. Recuperado de: https://www.abuelas.org.ar/noticia/brigada-de-san-justo-declararon-las-nietas-maria-y-maria-jose-lav alle-1032

9 Juzgado Federal Sec. N 2 de Morón, s/ “Gonzalez, Teresa Isabel, Rubén, Nelson s/infracción Art. 146 del Código Penal", Sentencia del 19/1/1988, p. 8.

10 Ibídem, p. 18.

11 Tercera audiencia del juicio por la Brigada de San Justo, 11/09/18, EcoRed Alternativo. Recuperado de: http://www.re deco.com.ar/nacional/ddhh/24851-tercera-audiencia-del-juicio-por-la-brigada-de-san-justo

12 La Dra. Marta Herrera consideró que a González le correspondía la pena de ocho años de prisión. Si bien coincidió en la calificación legal realizada por sus pares, la Jueza valoró como agravante el hecho de que González era Suboficial de la Policía en una Brigada donde "había presos políticos a los que tenía acceso directo, que existían en el país entidades que reclamaban por los desaparecidos y el resultados de los juicios que al respecto fueron de dominio público, configuran medios de apreciación más que suficientes para sospechar que la niña que recibieron podía ser hija de personas desaparecidas, no obstante lo cual los incusos no iniciaron búsqueda alguna de los posibles familiares, manifestando recién tal intención la González al ser indagada en las presentes actuaciones y en mi criterio con la única finalidad de intentar un argumento exculpatorio. (...) por lo que considero que González de algún modo se ha beneficiado de su condición de integrante de la policía para perpetrar el ilícito en cuestión”(pp. 92-93). No obstante, su voto no logró imponerse como mayoritario.

13 Circuito de CCD compuesto por el Club Atlético, el Banco y el Olimpo.

14 Juzgado Núm. 2 Sec. Núm. 3 de Buenos Aires, s/ "MIARA, Samuel y otra s/suposición de estado, civil, et.", Sentencia del 19/12/1995, p. 41

15 Ibídem, pp. 18-19. El subrayado es propio.

16 Cabe destacar que los magistrados a cargo de las causas analizadas en este trabajo fueron mayoritariamente hombres: intervinieron once jueces y dos juezas.

17 Juzgado Federal de San Isidro, Sentencia del 18/3/1993, pp. 7-8.

18 En el mes de mayo de 1994 los programas Memoria de Chiche Gelblung, H\&L de Daniel Hadad y Marcelo Longobardi y Tiempo Nuevo de Bernardo Neustadt emitieron transmisiones especiales dedicadas a la historia de "los mellizos Miara" en las cuales invitaron a los hermanos a "contar su historia”. Allí, los adolescentes expusieron su amor por Miara y Castillo y su enojo con el Juez Federal Jorge Luis Ballesteros por el hecho de tener que vivir con su tío biológico.

19 Tiempo Nuevo, 31/05/1994. El subrayado es propio. 
20 Juzgado Núm. 2 Sec. Núm. 3 de Buenos Aires, s/ "MIARA, Samuel y otra s/suposición de estado, civil, et.", Sentencia del 19/12/1995, p. 16.

21 La Querella y la Fiscalía difirieron en relación a la responsabilidad de Gómez Pinto en el delito de falsificación ideológica de instrumento público: mientras la Querella consideró que Rivas y Gómez Pinto eran coautores y que "ambos han querido insertar datos falsos en los documentos sin que resulte necesario que cada uno lleve adelante la totalidad de la conducta" (Tribunal Oral en lo Criminal Federal N 5 de Capital Federal, s/ "Rivas Osvaldo Arturo, Gomez Pinto Maria Cristina y Berthier Enrique Jose s/ sustracción de menores de 10 años (art. 146)”, Sentencia del 4/4/2008, p. 147); la Fiscalía sostuvo que el delito correspondía únicamente a Rivas ya que era quien lo había cometido y dado que se encontraba vigente la patria-potestad, disponiendo al padre como encargado de la inscripción del nacimiento de un hijo.

22 Tribunal Oral en lo Criminal Federal N ${ }^{\circ} 5$ de Capital Federal, s/ "Rivas Osvaldo Arturo, Gomez Pinto Maria Cristina y Berthier Enrique Jose s/ sustracción de menores de 10 años (art. 146)”, sentencia del 4/4/2008, p. 48.

23 Ibídem, p. 81.

24 Ibídem, p.164.

25 Ibídem, p. 98.

26 Ibídem, p.102.

27 Conferencia de prensa de María Eugenia Sampallo Barragán, 31/3/2008.

28 Tribunal Oral en lo Criminal Federal N 5 de Capital Federal, s/ "Rivas Osvaldo Arturo, Gomez Pinto Maria Cristina y Berthier Enrique Jose s/ sustracción de menores de 10 años (art. 146)”, Sentencia del 4/4/2008, p. 112. Resaltado en el original.

29 En la misma causa se juzgó a Héctor Salvador Giribone, ex-oficial militar de Campo de Mayo, por haber entregado a Pablo Gaona Miranda a su sobrino Salvador Norberto Giribone.

30 Tribuna Oral Federal Núm. 5 de Capital Federal, 16/9/2014, p. 101.

31 Entrevista realizada a Pablo Javier Gaona Miranda el 25 de abril de 2018 en la Ciudad de Buenos Aires. Entrevistadora: Ana Laura Sucari.

32 Tribunal Oral en lo Criminal Federal No 5 de Capital Federal, s/ "Giribone Salvador Norberto s/ sustracción y ocultamiento de un menor", Sentencia del 16/9/2014, p. 133. 